\title{
A Measuring Instrument for Ethical Sensitivity in the Therapeutic Sciences
}

\author{
Alida Naudé*, Juan Bornman \\ Centre for Augmentative and Alternative Communication, University of Pretoria, Pretoria, South Africa
}

Email address:

alida@lebonems.co.za (A. Naudé)

*Corresponding author

\section{To cite this article:}

Alida Naudé, Juan Bornman. A Measuring Instrument for Ethical Sensitivity in the Therapeutic Sciences. Humanities and Social Sciences. Special Issue: Ethical Sensitivity: A Multidisciplinary Approach. Vol. 4, No. 2-1, 2016, pp. 29-36. doi: 10.11648/j.hss.s.2016040201.15

Received: December 21, 2015; Accepted: December 23, 2015; Published: May 13, 2016

\begin{abstract}
An emerging literature in behavioural ethics conceptualized ethical sensitivity as a critical part of the decision making process. Ethical sensitivity together with an understanding of the client, their needs, emotions and circumstances is fundamental to an effective therapeutic relationship and competent practice. This study appears to be the first to empirically measure this concept in decision making related to the therapeutic sciences, including audiology, occupational therapy, physiotherapy and speech-language therapy. A multidisciplinary measure of ethical sensitivity is developed and consists of 12 vignettes that represent clinically relevant ethical issues related to these four professions. The study followed a two-phase, sequential mixed-methods research approach. Phase 1, the qualitative stage, focused on developing a measuring instrument by means of a systematic review of the following: ethical codes of conduct; focus group discussions; individual in-depth interviews; an expert panel review; and public complaints websites. Phase 2, the quantitative stage, focused on implementing and evaluating the measuring instrument. One hundred participants representing the four professions completed the instrument. Participants' overall scores on the Measuring Instrument for Ethical Sensitivity in the Therapeutic sciences (MIEST) were comparable for all four professions, confirming the multidisciplinary usability of the instrument. Participants were inclined to make grounded Beneficence centred decisions. Participants were particularly sensitive about the impact of the therapist's actions on the individual client, and sometimes overlooked their duty to the community. The MIEST can be used to assess the ethical sensitivity of student therapists (and possibly qualified therapists) and describe the stage of their ethical sensitivity development throughout the course of their professional development. The constructed vignettes make the MIEST appropriate for use in problem-based learning programmes.
\end{abstract}

Keywords: Ethical Principle, Ethical Sensitivity, Therapist, Perspective Taking, Beneficence

\section{Introduction}

Kushner [1] asserts that the perception of self rests on two basic, universal human needs: perceiving oneself as a good person and perceiving oneself as successful and important. Every human being possesses both good and bad tendencies and since society does not always celebrate virtuous behaviour, these two basic needs are often in conflict with each other. The attempt to satisfy the two needs can lead to inconsistency between how individuals want to act (intent) and their actual behaviour. This same conflict is seen in the therapeutic sciences. The challenge is to find a balance between the goal to succeed professionally and the desire to maximise the well-being of clients by providing them with effective products and services.

Professional ethics holds admirable ideals in tension with everyday professional workplace realities related to increasing accountability demands, resource challenges, global horizons of standards and developing techniques, shifting knowledge and changing client relationships, and how professionals navigate such turbulent situations or dissolve ethical dilemmas. The challenges to be faced are complex, contextually unique and frequently give rise to competing and conflicting struggles regarding values and ethical stances. Individual professionals have to rely on their own ability to reflect critically and make immediate ethically responsible decisions. This decision-making process involves 
ethical sensitivity, ethical judgment, and ethical choice [2]. Most discussions of ethical decision-making frameworks maintain that ethical sensitivity is the starting point in the process of ethical decision making and comes before the step of ethical reasoning.

What is ethical sensitivity and what does it entail? Ethical sensitivity can best be understood as the relative capacity to recognise the ethical dimensions within an ethical situation. However, clarification of what constitutes an ethical (decision-making) situation receives limited attention in the current published research literature. By most accounts, an ethical situation involves choice and will have a significant impact on the welfare of other people. Ethical situations are also defined by the ethical principles and guidelines of the profession, and the situation could be thought of as ethical to the extent that these principles and guidelines are relevant and deserve consideration in a particular situation. Ethical dimensions are those norms, standards and principles that provide the basic guidelines for determining how conflicts in human interests are to be settled and for optimizing mutual benefit of people living together in groups (Rest, 1986, p. 1) [3]. While perceiving or recognising the ethical dimensions of situations, one might assign relatively little importance to it (and in this sense be ethically insensitive). Unless the ethical aspects of a situation are perceived or recognised, it is hard to address any ethical problem, for without the initial recognition, no ethical problem exists. While ethical sensitivity is conceived as a critical factor in ethical decisionmaking, and can be operationalised because of an established and agreed-upon ethic of a profession, the construct of ethical sensitivity has not yet received dedicated and focused attention in studies that examine and discuss the level of ethical reasoning or ethical conduct in the therapeutic sciences. Furthermore, no related empirical studies have been conducted that attempt to measure ethical sensitivity either. The difficulty of measuring ethical sensitivity may be one of the major contributing obstacles that have prevented research in this area. This manuscript will describe the process used to develop a new ethical sensitivity measure. It is strictly professional, as it measures understanding or recognition of a professional code of ethics. The multidisciplinary measuring instrument is called "Measuring Instrument for Ethical Sensitivity in the Therapeutic sciences" (MIEST).

\section{The Construct of Ethical Sensitivity}

\subsection{Ethical Sensitivity in the Therapeutic Sciences}

Ethical sensitivity may be defined as a therapist's ability to recognise that an ethical problem exists. It includes the ability to identify both the client and situational needs. The key characteristics of ethical sensitivity are moral perception, affectivity and dividing loyalties. In short, moral perception is the ability to identify client and situational needs. Affectivity is a relational component based on the therapist putting herself/himself in the place of clients in order to identify and weigh comparable reactions. Dividing loyalties is about an awareness of moral and ethical principles, their significance in the context, and each stakeholder's needs and interests, and it involves using sources of knowledge (e.g. expert opinions, policies and professional conduct codes) to solicit breadth and depth about an issue [4]. These attributes enable therapists to recognise, understand, and evaluate ethical elements in clinical practice. The skills within ethical sensitivity, namely controlling social bias, responding to diversity, understanding emotional expression, taking the perspective of others, interpreting situations, relating to others and communicating effectively facilitate three main functions that include basic cognitive processes that can be taught.

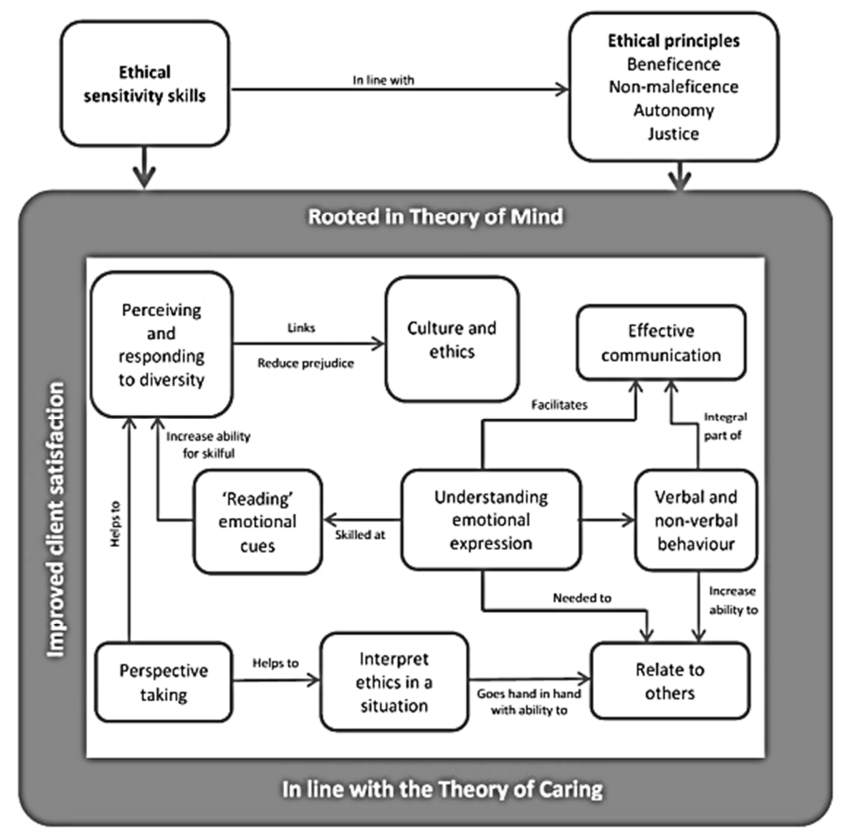

Figure 1. Interaction between ethical sensitivity skills within a framework.

The first function is acquiring information about the ethical situation. This includes processes of perception and inference such as reading and expressing emotions, as well as perspective taking. The second function relates to organising information. This includes processes of critical thinking and reflection such as caring by connecting to others, and working with interpersonal and group differences by controlling social bias. The last function is interpreting information and includes processes of divergent thinking and prediction through generating interpretations and options with special consideration for the consequences. The 'information' can represent an observed incident, perceived relationships, currently experienced emotions, background knowledge of events and relationships retrieved from memory, and present attitudes retrieved from memory $[5,6$, 7]. These three functions evolve into deeper, emotional skills as the therapist observes role modelling and gains personal reflective experiences. Ethical sensitivity skills include both skills that form part of personal development as well as skills for getting along with others. Therapists should know themselves and be able to control and guide 'the self' before 
being able to interact respectfully with others [8]. Ethical sensitivity skills, although named separately, directly influence each other as depicted in Figure 1.

\subsection{Why Should Ethical Sensitivity Be Measured in the Therapeutic Sciences}

More than ever before, therapists are confronted with complex ethical issues as part of daily practice. These include but are not limited to disagreements between clients, relatives and therapists over management decisions, truth telling and client confidentiality. Recognising the growing importance of ethical awareness stresses the importance of therapists who should be suitably trained in clinical ethics. This goes beyond the code of ethics for the specific discipline and focuses on clinical problems and practical decision making. Regardless of the objective formulated for a course in ethics (e.g. to develop moral character, to promote ethical decision-making skills, or to encourage the development of ethical therapists), ethical sensitivity is the first step in real-life moral decision making and cannot be ignored. Without recognising the ethical aspects of a situation, it is impossible to apply ethical problem solving, for without the initial recognition, no problem exists. Educational efforts should be aimed at improving the ethical sensitivity of professionals (both student therapists and practising therapists) with a specific focus on continued professional development. Ethics education is about recognising the real power of one's ethical sensitivity or instinctive ethical sense and how it influences one's decisions in everyday practice [9].

This dimension of decision making, namely recognising an ethical situation (or potential pitfall) has not received as much attention as specific models of decision making itself. Where ethical sensitivity was researched in healthcare professions, it mostly focused on medical doctors, psychiatrists and nurses. These studies also expressed the need for and importance of multiprofessional ethical sensitivity evaluation tools.
The development of a measure for ethical sensitivity that uses a consolidated definition and incorporates agreement from the different therapeutic science professions regarding the characteristics, boundaries and consequences of ethical sensitivity will facilitate optimal knowledge development related to care and services provided to clients [4]. The value of a measuring instrument that incorporates ethical issues and necessitates the identification of culturally based expectations has also been discussed. A measuring instrument for ethical sensitivity can help to broaden therapists' understanding of their own as well as other cultural perspectives in order to avoid or minimise misinterpretation of the behaviour of others. While ethical sensitivity is a critical factor in ethical decision making, no empirical studies have been conducted that attempt to measure ethical sensitivity in the therapeutic science, or explore the factors that may affect ethical awareness.

\section{Methodology for MIEST}

\subsection{Vignette Development}

The MIEST is a product of a qualitative exploration of ethical sensitivity as it relates to the therapeutic sciences. Phase 1 focused on developing a measuring instrument. The first step in meeting this aim consisted of a systematic review of published literature related to ethics in the field of audiology [10]. The ethical issues audiologists face involving the delicate balance between professional obligations and business principles have received a lot of attention in the literature. The authors' graduate training also allowed for deep insight into the literature related to ethics in audiology. The systematic review allowed for a comparison between research-related ethics in audiology and ethics in physiotherapy, as a systematic review on ethics knowledge in physiotherapy was done with literature published between 1970 and 2000 [11].

Table 1. Comparison of expert panel opinion regarding principles and skills represented in the vignettes.

\begin{tabular}{|c|c|c|c|c|c|c|c|c|c|}
\hline $\begin{array}{l}\text { Vignette number with target } \\
\text { principle/skill }\end{array}$ & A U D 1 & A U D 2 & O T 1 & O T 2 & P T 1 & P T 2 & S L T 1 & S L T 2 & $\begin{array}{l}\text { Total Correct options/ } \\
\text { Possible alternatives }\end{array}$ \\
\hline \multicolumn{10}{|l|}{5} \\
\hline Ethical principle: Justice & $\mathrm{J}$ & A & B & A & A & $\mathrm{J}$ & B & $\mathrm{J}$ & $3 / 8$ \\
\hline $\begin{array}{l}\text { Ethical skill: Controlling social bias } \\
14\end{array}$ & TP & RO & $\mathrm{CB}$ & $\mathrm{TP}$ & RO & $\mathrm{CB}$ & $\mathrm{CB}$ & $\mathrm{CB}$ & $4 / 8$ \\
\hline Ethical principle: Autonomy & A & A & A & A & B & A & A & A & $7 / 8$ \\
\hline Ethical skill: Effective communication & $\mathrm{EC}$ & $\mathrm{EC}$ & $\mathrm{EC}$ & $\mathrm{EC}$ & $\mathrm{EC}$ & $\mathrm{EC}$ & $\mathrm{TP}$ & $\mathrm{EC}$ & $7 / 8$ \\
\hline
\end{tabular}

Ethical principles: $A=$ Autonomy; $B=$ Beneficence; $J=$ Justice, Ethical skills: $C B=$ Controlling social bias; $E C=$ Effective communication; $R O=$ Relating to others; $T P=$ Taking the perspective of others.

Professional ethical codes reflect the ideals that various professional boards offer as necessary for ethical practice. Therefore, the second task related to the comparison of ethical codes from the therapeutic sciences to determine similarities and differences. We developed a grid of the ethical principles articulated by the professions of audiology, occupational therapy, physiotherapy and speech- language therapy. We attempted to build a measure that would embed ethical principles in depictions of acts of unprofessional behaviour. We identified four principles common to all professional codes that we reviewed.

The third task was to identify relevant ethical dilemmas, likely to result in ethically insensitive behaviour in practice and the creation of conceivable vignettes representing such acts. The focus was on both the view of the public and the professional. Summaries of website complaint platforms for 
the public were documented and grouped according to common identified themes. In addition, five separate focus groups (five to eight professionals with at least one professional from each of the therapeutic sciences) and eight individual in-depth interviews with experts in the different professions, and in ethics, were conducted. The collected data was used to construct the first 25 vignettes following the process of content analysis [12]. These twenty vignettes with five control (ethically neutral) vignettes, each targeting one of four ethical principles (autonomy, beneficence, justice and non-maleficence) and one of seven ethical sensitivity skills (controlling social bias, relating to others, taking the perspective of others, effective verbal communication, interpreting ethics in a situation, perceiving and responding to diversity and understanding emotional expression), were presented to therapists with expert knowledge and special interest in the field of ethics. During the expert panel review it became evident that twenty vignettes with five controls were too extensive for a 60 minute measuring instrument. After discussion with the experts, it was estimated that approximately twelve vignettes with three controls would be reasonable for a 60 minute measuring instrument. In order to eliminate eight vignettes and two controls, vignettes where the agreement between the target principle/skill and the experts' opinions were less than $75 \%(6 / 8)$ where excluded from the measuring instrument, as shown in Table 1.

The remaining vignettes were then scrutinised for distribution in terms of ethical principles and ethical sensitivity skills. The four target ethical principles were each used three times, while each of the seven ethical sensitivity skills were represented twice. During the final step, the 12 vignettes were marked according to level of difficulty based on the total score determined during the expert panel review. This was done to ensure that when the vignettes were randomised during the pilot study, the level of difficulty was distributed equally.

Phase 2, the quantitative phase, followed after the qualitative phase and had the purpose of evaluating the MIEST. Once the recommendations of the pilot study were implemented, the MIEST consisted of twelve vignettes, each stated in a single paragraph. The vignettes are intended to reflect a situation that a therapist is likely to encounter in professional practice.

\subsection{Scoring Rules}

A 7-point Likert scale score sheet was used by the participants to complete the MIEST (Table 2). Each of the 11 statements (four related to an ethical principle, and seven related to an ethical sensitivity skill) received a score. If the participants correctly identified the target ethical principle as applicable, they were awarded a score of $(+2)$. If they failed to identify the target principle, they were awarded a score of (-2). Negative marking was needed, as choosing an alternative ethical principle could result in unethical action and implies lowered ethical sensitivity of the participant. The score sheet also included "alternative options" for when a participant selected an ethical principle that was not targeted but that could be debated regarding its relevance, in which case a score of $(0)$ was awarded.

Since the identification of non-targeted ethical sensitivity skills in the vignette would not result in an unethical course of action, negative marking was not implemented as was the case with ethical principle identification. If the participants correctly identified the target ethical sensitivity skill, they were awarded a score of $(+2)$. If they identified an alternative possible skill, they were awarded a score of $(+1)$. If the skill was not relevant to the vignette, a score of $(0)$ was allocated. An example of how scoring was done is provided in Table 2.

Table 2. Comparison of expert panel opinion regarding principles and skills represented in the vignettes.

\begin{tabular}{|c|c|c|c|c|c|c|c|}
\hline Target ethical sensitivity skill & 0 & 0 & 0 & 0 & 2 & 2 & 2 \\
\hline Ethical sensitivity skill & 1 & 1 & 1 & 2 & 0 & 0 & 0 \\
\hline Target ethical principle & 2 & 2 & 2 & -2 & -2 & -2 & -2 \\
\hline Ethical sensitivity skill & 0 & 0 & 0 & 2 & 0 & 0 & 0 \\
\hline Target ethical sensitivity skill & 2 & 2 & 2 & 0 & 0 & 0 & 0 \\
\hline
\end{tabular}

In Table 2 the target responses are highlighted, showing that one target ethical principle and two target ethical sensitivity skills were related to Vignette 1 . In the last column, in the last row, both the minimum and maximum possible scores for the vignette are shown as an example.

The scoring criteria were developed by determining an acceptable level of performance. In accordance with the Health Professions Council of South Africa guidelines regarding ethics performance, the researcher selected a score of $>70 \%$ as an indicator for established ethical sensitivity skill. Generally, higher education requires a score of $>50 \%$ to pass any assessment and therefore $\leq 50 \%$ was labelled as unacceptable performance. Since it is recommended in literature that the distance between points should be equal, performance in the $61-70 \%$ range was described as emerging. This level would be acceptable for undergraduate students with limited clinical experience, but with presumably adequate theoretical knowledge. The performance level just below the acceptable performance range was consequently labelled as inadequate. Performance levels can be used to measure learning and to show or monitor professional growth pertaining to ethical sensitivity.

\subsection{Application of the MIEST}

During the 2014 academic year, the MIEST was administered to final year audiology, occupational therapy, physiotherapy and speech-language therapy student at a South African university.

One hundred participants contributed towards the main study, comprising 20 audiologists, 30 occupational therapists, 27 physiotherapists and 23 speech-language therapists. Ninety per cent of the participants were female with only 1 (5\%) male in the audiology group and $9(33 \%)$ males in the physiotherapy group. The average age across the participants was 22 years (range: 21-27 years), similar across the four groups. 


\section{Results}

\subsection{Reliability of Transcriptions, Scoring and Participant Responses}

The reliability with which the data was scored was assessed using inter-rater reliability as a measure. An independent observer (dually qualified speech-language therapist and audiologist enrolled for postgraduate studies, with 14 years of experience), verified $20 \%$ of randomly selected verbatim transcriptions of the focus groups and individual in-depth interviews for scoring accuracy. The inter-rater reliability was measured at $100 \%$ for both transcriptions and scoring. The likelihood that participants had randomly selected responses was determined with the use of the Excel NORMSDIST function. This Standard Normal Cumulative Distribution Function was used to test the following hypothesis:

$\pi_{0}$ Population proportion appropriate of ethical principle from the vignettes $=0.5$.

$\pi_{0}$ Population proportion appropriate of ethical principle from the vignettes $=>0.5$.
The results $(0.98>0.5)$ indicated that the likelihood of participants guessing what the correct answers were, was low, which increased the reliability of the responses.

\subsection{Coding and Scoring of Participant Responses}

The statistician coded the responses recorded on each Likert item manually as well as with the statistical software. There was a $100 \%$ match between the manually coded template and the software-generated printout. Following the scoring of participant responses by the researcher, the independent observer scored $20 \%$ of randomly selected responses. These scores from the determined MIEST responses were compared with those scored by the researcher, with $100 \%$ agreement.

\subsection{Description of Participants'MIEST Scores}

The overall performance of the participants in relation to the 12 vignettes (total score) was calculated for each vignette by awarding a value to each answer provided on the measuring instrument. The results presented in Table 3 are presented per vignette, starting with Vignette 1.

Table 3. Overall performance of participants.

\begin{tabular}{|c|c|c|c|c|c|c|c|c|}
\hline Vignette & $\begin{array}{l}\text { Ethical } \\
\text { principle }\end{array}$ & Ethical skill & Audiologist & $\begin{array}{l}\text { Occupational } \\
\text { therapist }\end{array}$ & Physiotherapist & $\begin{array}{l}\text { Speech- } \\
\text { language } \\
\text { therapist }\end{array}$ & $\begin{array}{l}\text { ANOVA test } \\
\text { p-value }\end{array}$ & $\begin{array}{l}\text { Multiple } \\
\text { pairwise } \\
\text { comparison }\end{array}$ \\
\hline 1 & Justice & $\begin{array}{l}\text { Perspective } \\
\text { taking } \\
\text { Interpreting } \\
\text { ethics in a } \\
\text { situation }\end{array}$ & $\begin{array}{l}8 \\
\text { Emerging }\end{array}$ & $\begin{array}{l}10 \\
\text { Emerging }\end{array}$ & $\begin{array}{l}5 \\
\text { Inadequate }\end{array}$ & $\begin{array}{l}8 \\
\text { Emerging }\end{array}$ & $0.00032<0.05^{*}$ & $\mathrm{~F}=5.3, \mathrm{p}<0.05$ \\
\hline 2 & Autonomy & $\begin{array}{l}\text { Relating to } \\
\text { others } \\
\text { Emotional } \\
\text { expression }\end{array}$ & $\begin{array}{l}11 \\
\text { Emerging }\end{array}$ & $\begin{array}{l}11 \\
\text { Emerging }\end{array}$ & $\begin{array}{l}10 \\
\text { Emerging }\end{array}$ & $\begin{array}{l}10 \\
\text { Emerging }\end{array}$ & $0.08974>0.05$ & \\
\hline 3 & Beneficence & $\begin{array}{l}\text { Effective } \\
\text { communication } \\
\text { Emotional } \\
\text { expression }\end{array}$ & $\begin{array}{l}8 \\
\text { Emerging }\end{array}$ & $\begin{array}{l}11 \\
\text { Emerging }\end{array}$ & $\begin{array}{l}9 \\
\text { Emerging }\end{array}$ & $\begin{array}{l}10 \\
\text { Emerging }\end{array}$ & $0.1495>0.05$ & \\
\hline 4 & Non-maleficence & $\begin{array}{l}\text { Perspective } \\
\text { taking }\end{array}$ & $\begin{array}{l}1 \\
\text { Inadequate }\end{array}$ & $\begin{array}{l}5 \\
\text { Inadequate }\end{array}$ & $\begin{array}{l}2 \\
\text { Inadequate }\end{array}$ & $\begin{array}{l}2 \\
\text { Inadequate }\end{array}$ & $0.01<0.05^{*}$ & $\mathrm{~F}=3.44, \mathrm{p}<0.05$ \\
\hline 5 & Justice & $\begin{array}{l}\text { Relating to } \\
\text { others }\end{array}$ & $\begin{array}{l}7 \\
\text { Emerging }\end{array}$ & $\begin{array}{l}9 \\
\text { Emerging }\end{array}$ & $\begin{array}{l}7 \\
\text { Emerging }\end{array}$ & $\begin{array}{l}9 \\
\text { Emerging }\end{array}$ & $0.1654>0.05$ & \\
\hline 6 & Autonomy & $\begin{array}{l}\text { Effective } \\
\text { communication }\end{array}$ & $\begin{array}{l}7 \\
\text { Emerging }\end{array}$ & $\begin{array}{l}7 \\
\text { Emerging }\end{array}$ & $\begin{array}{l}5 \\
\text { Inadequate }\end{array}$ & $\begin{array}{l}9 \\
\text { Emerging }\end{array}$ & $0.0304<0.05^{*}$ & $\mathrm{~F}=4.2, \mathrm{p}<0.05$ \\
\hline 7 & Beneficence & $\begin{array}{l}\text { Emotional } \\
\text { expression }\end{array}$ & $\begin{array}{l}11 \\
\text { Emerging }\end{array}$ & $\begin{array}{l}9 \\
\text { Emerging }\end{array}$ & $\begin{array}{l}10 \\
\text { Emerging }\end{array}$ & $\begin{array}{l}11 \\
\text { Emerging }\end{array}$ & $0.1484>0.05$ & \\
\hline 8 & Non-maleficence & $\begin{array}{l}\text { Controlling } \\
\text { social bias }\end{array}$ & $\begin{array}{l}8 \\
\text { Emerging }\end{array}$ & $\begin{array}{l}11 \\
\text { Emerging }\end{array}$ & $\begin{array}{l}9 \\
\text { Emerging }\end{array}$ & $\begin{array}{l}10 \\
\text { Emerging }\end{array}$ & $0.3013>0.05$ & \\
\hline 9 & Justice & $\begin{array}{l}\text { Responding to } \\
\text { diversity }\end{array}$ & $\begin{array}{l}9 \\
\text { Emerging }\end{array}$ & $\begin{array}{l}10 \\
\text { Emerging }\end{array}$ & $\begin{array}{l}8 \\
\text { Emerging }\end{array}$ & $\begin{array}{l}11 \\
\text { Emerging }\end{array}$ & $0.0197<0.05 *$ & $\mathrm{~F}=2.8, \mathrm{p}<0.05$ \\
\hline 10 & Autonomy & $\begin{array}{l}\text { Responding to } \\
\text { diversity }\end{array}$ & $\begin{array}{l}11 \\
\text { Emerging }\end{array}$ & $\begin{array}{l}11 \\
\text { Emerging }\end{array}$ & $\begin{array}{l}11 \\
\text { Emerging }\end{array}$ & $\begin{array}{l}10 \\
\text { Emerging }\end{array}$ & $0.2758>0.05$ & \\
\hline 11 & Beneficence & $\begin{array}{l}\text { Controlling } \\
\text { social bias }\end{array}$ & $\begin{array}{l}6 \\
\text { Emerging }\end{array}$ & $\begin{array}{l}6 \\
\text { Emerging }\end{array}$ & $\begin{array}{l}3 \\
\text { Inadequate }\end{array}$ & $\begin{array}{l}7 \\
\text { Emerging }\end{array}$ & $0.0106<0.05 *$ & $\mathrm{~F}=3.9, \mathrm{p}<0.05$ \\
\hline 12 & Non-maleficence & $\begin{array}{l}\text { Interpreting } \\
\text { ethics in a } \\
\text { situation }\end{array}$ & $\begin{array}{l}7 \\
\text { Emerging }\end{array}$ & $\begin{array}{l}7 \\
\text { Emerging }\end{array}$ & $\begin{array}{l}7 \\
\text { Emerging }\end{array}$ & $\begin{array}{l}5 \\
\text { Inadequate }\end{array}$ & $0.4710>0.05$ & \\
\hline
\end{tabular}

*Indicates statistical significance on the $5 \%$ level of confidence $(\mathrm{p}<0.05)$ 
The target ethical principle and ethical skill(s) are specified in column 2 and 3 , followed by the total mean score with performance level for the four therapeutic sciences individually. Next, the research question was asked, namely whether there was a significant difference in the population proportions of the mean scores. In order to answer the research question, inferential statistics with analysis of variance (ANOVA) were used to test the hypothesis of $\mathrm{H}_{0}$ at a $5 \%$ level of significance.

$H_{0}$ The population mean score is the same across the four professions forming part of the therapeutic sciences.

$H_{1}$ The population mean score differs across the four professions forming part of the therapeutic sciences.

If $\mathrm{H}_{0}$ was rejected, multiple pairwise comparisons were conducted to determine which professions' mean scores were statistically significant. Post hoc analyses using the Scheffé post hoc criterion for significance (alpha $=0.05$ ) were used for this purpose.

\subsection{Significant Findings Emerging from Data Analysis}

Half of the 12 vignettes revealed statistical significant results between the four groups. In three vignettes, speechlanguage therapist presented with the highest total score. Speech-language therapy participants performed significantly better in comparison to physiotherapy participants in three vignettes $(6,8,11)$. Vignettes 8 and 11 both target the ethical skill of Controlling Social Bias, whilst Vignette 6 targets the ethical skill of Effective Communication. In two vignettes, speech-language therapist obtained the lowest score in relation to the four groups, although it was not statistically significant. The lower ethical sensitivity related to the principle of Autonomy and interpreting ethics in a situation (ability to generate numerous interpretations of a situation and considering alternatives for dealing with it). Overall, the four professional groups performed similarly in relation to the MIEST with statistically significant differences in only five of the vignettes $(1,4,6,8,11)$ on the $5 \%$ level of confidence $(p<0.05)$. Occupational therapy participants performed significantly better than physiotherapy participants in two of the vignettes $(1,4)$. Both of these vignettes incorporate the ethical skill of Perspective Taking. Overall scores on the MIEST were lowest on Vignette 4 for all four professions, followed by Vignette 12, indicating that participants experienced these two vignettes as the most challenging. The target ethical principle for both Vignettes 4 and 12 is Non-Maleficence. The overall scores on the MIEST in relation to all 12 vignettes showed comparable total average scores for audiology participants (7.8), occupational therapy participants (8.9), physiotherapy participants (7.1) and speech-language therapy participants (8.5) respectively.

\section{Discussion}

The application of the MIEST across four therapeutic science student cohorts at a specific university which trained all of these professions provided several interesting results. The first relates to participant scores for individual vignettes in relation to suggested difficulty levels obtained from the individual interviews with experts in the field. On two of the vignettes (Vignettes 4 and 8) which experts identified as easy, the participants performed poorly. Sparks and Hunt (1998) offer a possible explanation for this by pointing out that ethical sensitivity is a skill, developed through learning and socialisation, in a particular sphere of life. Although the students participating in this study had only recently completed their training in ethics, this exposure could have been insufficient to raise their awareness of the ethical issues involved in these two cases. Both vignettes targeted the ethical principle of Non-Maleficence. The two vignettes depicted the therapist as someone trying to do good and assuming the perspective of the client. This is essential information for developing ethical sensitivity in the therapeutic sciences as it emphasises the importance of realising that even though Beneficence is a central principle in the therapeutic sciences (and often the principle overemphasised in ethics training), it must always be balanced by considering the principle of Non-Maleficence. Blindly following the principle of Beneficence could result in unethical (or unlawful) practice, even if unintentional.

In contrast to Vignettes 4 and 8, participants performed well on two vignettes that the experts classified as difficult. These two (Vignettes 6 and 10) clearly showed aspects of Beneficence as well as Confidentiality, with the target principle being Autonomy. The students who participated probably found it easy as these vignettes could be related to an ethics of care [14]. The additional focus in all the therapeutic science professions on instructing students with regard to Autonomy would also make participants more sensitive to violations of Autonomy. Both Beneficence and Autonomy are considered to be fundamental principles of ethics [15]. Emotional aspects related to clinical practice, for example the therapist's feelings concerning clients who are uninvolved in the therapy process, or building relationships with the family of the client, are probably more foreign to students, whilst this emotion inhibits the ethical sensitivity of experienced therapists. Therapists have to put their own bias and personal feelings aside, which complicates the ethical implications in the vignette. Reflection and discussion of these types of vignettes as part of continued professional development will increase therapists' sensitivity to the ethical dimensions often masked by emotion.

In relation to the MIEST, speech-language therapy participants displayed exceptional insight into the ethical sensitivity skill Controlling (Disability) Social Bias. Due to extensive linguistic and cultural diversity in the world, there is a specific need for culturally valid and reliable developmental assessment tools that can accommodate the diversity of the population. Speech-language therapists are specifically trained to view the client holistically and consider the impact of his/her cultural (a way of life of a specific group of people) and 
linguistic background. Developmental assessments should never be tests of cultural knowledge $[16,17]$.

Cultural awareness will influence a therapist's ability to control social bias and respect diversity. The level of awareness is considered a developmental process that evolves over time through the process of attaining cultural knowledge. Cultural awareness involves internal changes associated with the qualities of openness and flexibility in relation to others. All individuals are at various levels of awareness, knowledge and skills along the cultural competence continuum. Milton Bennett [18] constructed a developmental model of intercultural sensitivity in which he examined attitudes towards intercultural sensitivity and how these related to intercultural competence. Intercultural sensitivity is viewed as occurring along a continuum consisting of six different levels, as shown in Figure 2.

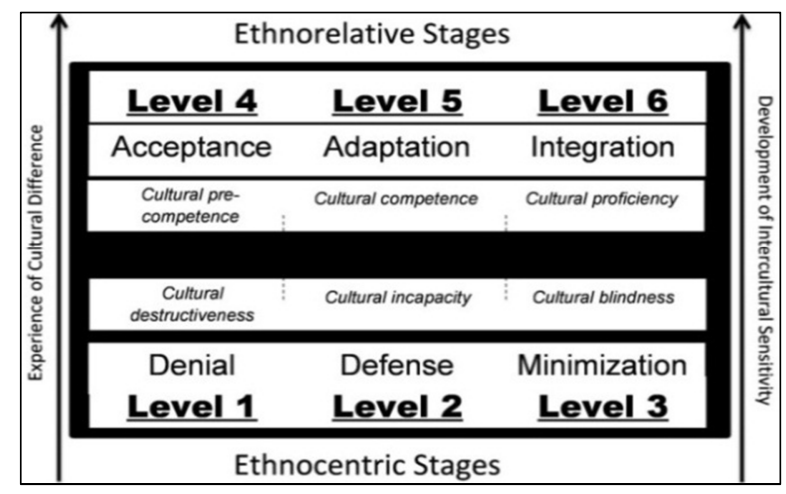

Figure 2. Intercultural sensitivity continuum

In terms of the overall score related to ethical sensitivity pertaining to controlling social bias Occupational therapists, as a group, are considered to function in the adaptation stage of this model, with the remaining three professions functioning in the acceptance stage of this model. The ethical sensitivity towards factors related to cultural competence will greatly benefit this professional group in the diverse cultural setting most therapists find themselves.

\section{Conclusion}

When measuring ethical sensitivity, it is important to identify the scope of the instrument. MIEST, as described in this paper, measures ethical sensitivity in relation to ethical issues within the therapeutic sciences. A primary objective of this research was to construct and subsequently apply a multi-disciplinary instrument. All participants completed the MIEST within 60 minutes. An experienced scorer can score around five protocols per hour. Participants' overall scores on the MIEST were comparable for audiologists, occupational therapists, physiotherapists and speech-language therapists, confirming the multidisciplinary usability of the MIEST. The MIEST presents an original approach to examining ethical sensitivity in therapists.

Theoretically grounded in the first step of Rest's [16] fourcomponent model and based on principles identified in codes of professional ethics, the MIEST can be used to investigate the relative impact of training courses in ethics in terms of the development of ethical sensitivity. The custom-developed vignettes provide a stable platform for training workshops based on the principles of problem-based learning, which are considered effective for the development of deeper competency in adult learners [17].

This study demonstrates that a measuring instrument that asks therapists to identify ethical issues by using vignettes has the potential to discriminate between participants in each therapy group, as well as between therapy groups. The authors seeked to describe the extent to which final-year students in the therapeutic sciences are aware of the ethical dimensions of dilemmas and the principle(s) on which they mostly base their decisions. The research study clearly demonstrated that final year students in the therapeutic sciences reflect a range of sensitivity to ethical issues embedded in the vignettes that were developed for the MIEST. This suggests that although they are not yet sensitive to all ethical concerns, they have a solid foundation to build on as they gain experience in their profession.

\section{Acknowledgements}

The financial assistance of the National Research Foundation (NRF) towards this research is hereby acknowledged. Opinions expressed and conclusions arrived at, are those of the author and are not necessarily to be attributed to the NRF. The assistance of Dr. Liebie Louw and Mrs. Joyce Jordaan with the statistical analysis of the data is gratefully acknowledged.

\section{References}

[1] Kushner H. Living a life that matters: resloving the conflict between conscience and success. New York: Knopf; 2001.

[2] Wittmer D. Developing a behavioral model for ethical decision making in organizations: conceptual and empirical research. In: Frederickson GH, Ghere RK, editors. Ethics in public management. New York: M.E. Sharpe, Inc; 2005. p. 49-69.

[3] Rest J. Moral development: advances in research and theory. New York: Praeger; 1986.

[4] Weaver W. Ethical sensitivity: state of knowledge and needs for further research. Nurs Ethics. 2007; 14 (2): 141-55.

[5] Crick N, Dodge K. A review and reformulation of social information processing in children's social adjustment. Psychol Bull. 1994; 115: 74-101.

[6] Ledoux J. The emotional brain. New York: Simon Schuster; 1996.

[7] Narvaez D. Moral perception: a new construct? Annual meeting of the American Educational Research Association. New York; 1996.

[8] Narvaez D, Endicott L. Ethical sensitivity: nurturing character in the classroom. Notre Dame, Indiana: Alliance for catholic education press; 2009. 
[9] Tiatorio A. Ethics workbook. Massachusetts: EthicsinEducation; 1999.

[10] Naudé AM, Bornman J. A systematic review of ethics knowledge in audiology (1980-2010). Am J Audiol [Internet]. American Speech-Language-Hearing Association; 2014 Jun 1 [cited 2014 Nov 5]; 23 (2): 151-7. Available from: http://aja.pubs.asha.org/article.aspx?articleid=1859494.

[11] Swisher LL. Research Report A Retrospective Analysis of Ethics. Phys Ther J Am Phys Ther Assoc. 2002; 82: 692-706.

[12] Naudé AM. Exploring ethical sensitivity in the South African context: developing and implementing a measure in the therapeutic sciences. University of Pretoria; 2015.

[13] Sparks JR, Hunt S. Marketing researcer ethical sensitivity: conceptualization, measurement and exploratory investigation. J Mark. 1998; 62: 92-109.
[14] Agarwal J, Malloy D. An integrated model of ethical decisionmaking: a proposed pedagogical framework for a marketing ethics curriculum. Teach Bus Ethics. 2002; 6 (2): 245-68.

[15] Bennett M. Towards ethnorelativism: a developmental model of intercultural sensitivity. In: Paige R, editor. Education for the intercultural experience. Yarmouth, ME: Intercultural press; 1993.

[16] Rest J. Morality. In: Flavell J, Markman E, editors. Handbook of child psychology. 4th ed. New York: John Wiley; 1983. p. 556-629.

[17] Harasym P, Tsai T, Munshi F. Is problem-based learning an ideal format for developing ethical decision skills? Kaohsiung J Med Sci. 2013; 29 (10): 523-9. 